\title{
Characterization of Citrus tristeza virus Single-Variant Sources in Grapefruit in Greenhouse and Field Trials
}

Glynnis Cook, Stephanus P. van Vuuren, Johannes H. J. Breytenbach, and Chanel Steyn, Citrus Research International, Nelspruit, 1200, South Africa; Johan T. Burger, Department of Genetics, Stellenbosch University, Matieland, 7602, South Africa; and Hans J. Maree, Agricultural Research Council, Infruitec-Nietvoorbij: Institute for Deciduous Fruit, Vines and Wine, Stellenbosch, 7599, South Africa, and Department of Genetics, Stellenbosch University, Stellenbosch, South Africa

\begin{abstract}
Cook, G., van Vuuren, S. P., Breytenbach, J. H. J., Steyn, C., Burger, J. T., and Maree, H. J. 2016. Characterization of Citrus tristeza virus single-variant sources in grapefruit in greenhouse and field trials. Plant Dis. 100:2251-2256.

Citrus tristeza virus (CTV) is endemic to southern Africa and the stem pitting syndrome that it causes was a limiting factor in grapefruit production prior to the introduction of cross-protection in the Citrus Improvement Scheme. This disease mitigation strategy, using various field-derived CTV sources, has significantly extended the productive lifespan of grapefruit orchards in South Africa. CTV commonly occurs as a population of various strains, masking the phenotypic effect of individual strains. Likewise, current South African CTV cross-protection sources are strain mixtures, obscuring an understanding of which strains are influencing cross-protection. The severity of various CTV strains has mostly been assessed on sensitive indicator hosts, but their effect on commercial varieties has seldom been investigated. Single-variant CTV isolates were used to investigate the phenotypic expression of CTV strains in commercial grapefruit varieties as well as CTV indicator hosts. They were biologically characterized for their ability to cause stem pitting and their rate of translocation

and titer in the different hosts, monitored by enzyme-linked immunosorbent assay. Complete genome sequences for three CTV strain variants were generated. Isolates of CTV strains VT, T68, RB, and HA16-5 did not induce severe stem pitting in four grapefruit hosts in a glasshouse trial. Viral titers of the strains differed in the grapefruit hosts, but the RB isolate reached a higher titer in the grapefruit hosts compared with the VT, T68, and HA16-5 isolates. Additionally, horticultural assessment of two grapefruit varieties inoculated with the RB isolate in two field trials demonstrated that mild stem pitting did not negatively influence the horticultural performance of the grapefruit trees over an eight-year assessment period. 'Star Ruby' trees containing the CTV source GFMS35 showed less stem pitting than trees inoculated with the RB isolate, but had smaller canopy volumes and lower yields than trees containing the $\mathrm{RB}$ isolate. This suggests that the influence of CTV sources on tree performance is not limited to the effect of stem pitting.
\end{abstract}

Citrus tristeza virus (CTV) is a member of the family Closteroviridae, with an approximately 19.3-Kb genome (Karasev et al. 1995) that displays significant sequence variation among currently known strains (Harper 2013). The genotypic characterization of CTV variants has progressed significantly, but their phenotypic expression in various citrus varieties is less defined. Fundamental work in CTV is mainly done on sensitive biological indicator hosts in which symptom expression is faster and more definitive. However, these results cannot be extrapolated to commercial citrus varieties with varying CTV susceptibility, as symptom expression can be host-dependent.

CTV can cause a stem pitting syndrome in the trunks and limbs of grapefruit (Citrus paradisi) trees that are established on rootstocks other than sour orange (C. aurantium). The resulting disruption of vascular flow leads to a gradual tree decline and is often associated with lower yield and a decrease in fruit size, impacting exportability of the fruit. This is contrasted to the quick decline syndrome or 'Tristeza' associated with trees grafted on sour orange rootstocks. This stem pitting syndrome necessitates earlier tree rotation resulting in financial losses associated with tree replacement and production lag. Different phenotypes of stem pitting are found in citrus, including

Corresponding author: G. Cook; E-mail: glynnis@cri.co.za

Nucleotide sequence data is available in the GenBank database under accession numbers KU883265, KU883266 and KU883267.

*The $\boldsymbol{e}$-Xtra logo stands for "electronic extra" and indicates that a supplementary figure and a supplementary table are published online.

Accepted for publication 22 May 2016.

http://dx.doi.org/10.1094/PDIS-03-16-0391-RE

(C) 2016 The American Phytopathological Society large grooves visible on tree trunks and limbs, 'honey-comb' stem pitting, referring to a high density of small pits, which is more damaging to the tree, and a spectrum between these two phenotypes (Moreno and Garnsey 2010). The requirements for stem pitting development are not fully understood, but expression of the CTV p33, p13, and possibly the p18 genes appear to be involved (Tatineni and Dawson 2012). Expression of the same genes by CTV strains in varying combinations is required for infection of certain citrus species (Tatineni et al. 2011). These findings imply very specific interactions of strains with various citrus hosts that influence host susceptibility.

Apart from South Africa, 'mild-strain' cross-protection is successfully applied to reduce the effect of CTV stem pitting on commercial citrus by a number of citrus-producing countries, including Australia (Broadbent et al. 1991), Brazil (Salibe et al. 2002), and Peru (Bederski et al. 2005). CTV control by eradication of infected trees is not feasible in southern Africa due to the endemic presence of the brown citrus aphid Toxoptera citricida, the most efficient aphid vector of CTV. The South African Citrus Improvement Scheme implemented crossprotection to minimize losses incurred due to stem pitting, primarily in grapefruit. This management strategy has significantly extended the productive lifespan of grapefruit orchards in South Africa by minimizing losses incurred due to stem pitting (Marais 1994).

A strain-specific exclusion mechanism, superinfection exclusion (SIE), has been demonstrated and proposed as a possible mechanism for cross-protection (Folimonova et al. 2010). It was established that, once a plant is infected with a certain strain, a challenge virus of the same strain is not able to infect the plant. This exclusion is not applicable to dissimilar strains and relies on a homologous p33 viral protein of the same strain (Folimonova 2012). Additionally, it was demonstrated that two leader proteases, L1 and L2, are also involved in SIE (Atallah et al. 2016). This mechanism has not been completely resolved on a biological level, as the existence of a 'mild' variant of a pathogenic strain is required to prevent infection of 'severe' variants. If this is the mechanism at work in cross-protection, ultimate 
cross-protection would require a 'mild' variant of each pathogenic strain for effective cross-protection. The requirement for the existence of 'severe' and 'mild' variants of strains has not been demonstrated in CTV. It is, therefore, important to resolve which strains and strain variants are pathogenic in a specific citrus host and which mitigate disease expression in cross-protection. Current cross-protecting sources used in the South African industry were empirically selected and comprise strain mixtures (Cook et al. 2016), which makes it difficult to ascribe cross-protection to specific strains.

Given the above, empirical studies are required to investigate the influence of CTV variants in specific citrus varieties. CTV components of various sources were previously subisolated by single aphid transmission (SAT), and one single-strain isolate was identified after conclusion of a shoot-tip grafting process. These CTV isolates were characterized as single-variant sources in this study. Complete genome sequencing was complemented by biological assessment on a grapefruit host range to evaluate the pathogenicity, translocation, and titer of each variant in four grapefruit varieties. One of these subisolates was included in grapefruit cross-protection field trials and horticultural data regarding canopy volume, yield, and fruit size of trees inoculated with this source were compared with other CTV sources used in these trials. The CTV sources used could, unfortunately, not be assessed for their effectiveness to cross-protect against pathogenic strains in these trials due to a lack of natural challenge at these sites.

The characterization of single-variant CTV sources is foundational to further complementation and cross-protection studies, and the genome characterizations also add to the known diversity of CTV variants. This work provides biological data of characterized strainvariants on commercial grapefruit varieties and indicator hosts.

\section{Materials and Methods}

Biological and molecular strain characterization. Four CTV sources were characterized: (i) 'Maxi', derived from Valencia orange (Citrus sinensis), subisolated in a shoot-tip grafting process, (ii) GFMS12-8, a subisolate obtained by SAT from the cross-protection source GFMS12 (originally derived from 'Nartia' grapefruit) (van Vuuren et al. 2000), (iii) LMS6-6, subisolated by SAT from the crossprotection source LMS6 (originally obtained from 'Mexican' lime [C. aurantifolia]) (van Vuuren et al. 2000), and (iv) B390-5, a subisolate obtained by SAT from a 'Mouton' Valencia orange source (L. J. Marais, Citrus Research International research records). The presence of other viruses, citrus viroids, and 'Candidatus Liberibacter africanus' were excluded by biological indexing, reverse transcriptionpolymerase chain reaction (RT-PCR), and PCR (Supplementary Table S1).

Each source was bark-inoculated onto a citrus host range including 'Madam Vinous' sweet orange, sour orange, 'Mexican' lime and 'Duncan' grapefruit. The host range was used to determine single variant status by eliminating the possible suppression of strains in certain hosts. Each host was tested with eight strain-specific RT-PCRs and PCR amplicons sequenced as previously described (Cook et al. 2016). Single-variant status was further verified by using degenerate primers to amplify a midgenome region containing sufficient sequence variability to allow for differentiation of strains (Roy and Brlansky 2010). Amplification and direct Sanger sequencing of a 1,535-bp product was done for each isolate using primers CTVmid-F, 5'GAACCGGCTCGYGTTCGGCGT3', and CTVmid-R, 5'GCAAACATCYYGACTCAACTACC3', to allow detection of possible mixtures. Reactions were performed as above and primer annealing was at $60^{\circ} \mathrm{C}$.

Direct Sanger sequencing of overlapping amplicons of approximately $1,500 \mathrm{bp}$ was used to generate complete genome sequences of the single-strain variants, except for GFMS12-8, which was previously determined (KC333868) (Zablocki and Pietersen 2014). Overlapping primer sets were designed for the VT, HA16-5, and RB strains based on the strains identified with the strain-specific RT-PCRs for 'Maxi', LMS6-6, and B390-5, respectively. RNA was extracted from the 'Mexican' lime hosts for sequencing. RT was done as above and PCR amplification was done using KAPA HiFi
HotStart ReadyMix (KAPA Biosystems), as per supplier's protocol. PCR products were gel-purified using the ZYMOCLEAN Gel DNA recovery kit (Zymo Research Corporation) and were sequenced in both directions. To generate the complete genomes, low-quality bases were removed and the overlapping sequences were aligned using BioEdit (Hall 1999). The most distal 5' and $3^{\prime}$ primer sequences were included in the sequences, as these regions could not be verified by overlapping sequences. Closest sequence identity of genomes were determined using BLAST (Altschul et al. 1990).

A neighbor network of the complete genomes of the four CTV isolates and 47 CTV complete genome sequences available on GenBank was constructed. Alignments were done using CLC Main workbench 7 (Qiagen). The network was constructed with SplitsTree v4 (Huson and Bryant 2006), which uses the "Unrooted Equal angle" algorithm (Dress and Huson 2004) with equal-daylight and box-opening optimization (Gambette and Huson 2008).

Host-range symptom assessment. The presence of stem pitting was assessed in two red, 'Star Ruby' and 'Nel Ruby', and two white, 'Marsh' and 'Duncan', grapefruit varieties as well as 'Mexican' lime, the biological indicator host. Virus-free rough lemon (C. jambhiri) seedlings were planted singly in 3-liter planting bags and were maintained in an aphid-free polycarbonate tunnel equipped with wet-wall cooling. Virus-free scions of the grapefruit varieties were bud-grafted to rootstocks according to normal nursery practices and 'Mexican' lime plants were grown from seed. The four single variants were inoculated separately to five plants of each variety and a minimum of four plants were left as uninoculated controls. Inoculation was done by patch-grafting two bark chips of the source plant to the scion. All plants were inoculated at the same height and, after inoculation, the scions were cut back approximately $10 \mathrm{~cm}$ above the inoculation points and one shoot of the new growth was allowed to grow from the top bud. Plants were cut back at four intervals and were evaluated for stem pitting and one shoot of new growth was allowed to grow out each time. The first cut back was after 6 months followed by 10-, 11-, and 8-month intervals.

Enzyme-linked immunosorbent assay (ELISA). Translocation and titer differences of the CTV single variants were monitored in the grapefruit and 'Mexican' lime hosts by semiquantitative ELISA tests. Leaves of each plant were sampled at three different postinoculation intervals: (i) 7 weeks postinoculation (wpi), $15 \mathrm{~cm}$ above the inoculation point; (ii) $13 \mathrm{wpi}, 30 \mathrm{~cm}$ above inoculation point; and (iii) $24 \mathrm{wpi}$, at the top of the plant. The SRA 78900 CTV ELISA reagent set (Agdia, Inc.) was used as per supplier's protocol. A total of $400 \mathrm{mg}$ of leaf material including midribs were used per sample and were macerated in 4-ml of general extraction buffer in maceration bags, using a power homogenizer. Results were recorded by measuring absorbance values at $405 \mathrm{~nm}$ after $30 \mathrm{~min}$ incubation at room temperature.

Field trial assessment of B390-5 on grapefruit. Isolate B390-5 was assessed for field performance in two grapefruit field trials, evaluating potential CTV cross-protection sources. Trial trees were prepared by bud-grafting virus-free 'Star Ruby' and 'Marsh' to 'Troyer' citrange rootstocks. Scions were inoculated by patch-grafting with the various CTV sources including B390-5, GFMS12, and GFMS35, the standard cross-protection source currently used for grapefruit in South Africa. GFMS12 was previously used as the grapefruit crossprotection source (van Vuuren and Manicom 2005). Control trees were not inoculated. Inoculations were confirmed by ELISA 3 months postinoculation. The trees were planted in 2007 in two different sites, according to a randomized block design with five replicates for each treatment. The 'Star Ruby' trial was planted in the Letsitele area in Limpopo province (South Africa) and the 'Marsh' trial in the Malelane area in Mpumalanga province (South Africa). These regions differ in climate. Letsitele is a hot and dry region, whereas the Malelane region is hot and humid. The trees were evaluated annually for the development of stem pitting, and tree canopy volumes were determined using the formula $\mathrm{V}=\mathrm{S}^{2}(\pi \mathrm{h}-1.046 \mathrm{~S})$, where $\mathrm{S}$ is canopy radius and $h$ is the height of the fruit-bearing canopy (Burger et al. 1970). Fruit yield (kilograms per tree) was measured annually and a 3-year 
cumulative yield per tree for the sixth to eighth year obtained. Fruit size distribution was determined at harvest according to export size categories, and fruit of $83 \mathrm{~mm}$ in diameter and smaller was regarded as small fruit. Stem pitting was evaluated externally, using a severity scale of 0 to 3 , where 0 represents a smooth trunk with no visible pits, 1 represents one to three grooves on the stem, 2 indicates multiple grooves, and 3 is severe stem pitting in which the tree trunk has a knotted appearance (Supplementary Fig. S1). This knotted trunk is associated with honey-comb stem pitting that can be seen by the removal of the bark, but bark removal was not done at each evaluation point. Stem pitting ratings and tree canopy volume measurements for the eighth year in the field are presented. Calculations for analysis of variance and least significant difference (Fisher's least square difference) were performed using XLSTAT 2015.5.01.23039 (Addinsoft).

Table 1. Stem pitting presence on four grapefruit varieties and the 'Mexican' lime indicator host inoculated with the Citrus tristeza virus (CTV) single-variant sources $^{\mathrm{z}}$

\begin{tabular}{lccccc}
\hline $\begin{array}{l}\text { CTV single- } \\
\text { variant }\end{array}$ & 'Duncan' & 'Marsh' & 'Nel Ruby' & 'Star Ruby' & $\begin{array}{c}\text { Mexican' } \\
\text { lime }\end{array}$ \\
\hline B390-5 & + & + & + & + & + \\
'Maxi' & + & + & + & + & + \\
LMS6-6 & - & - & - & - & + \\
GFMS12-8 & + & + & + & + & + \\
Control & - & - & - & - & - \\
\hline
\end{tabular}

${ }^{\mathrm{z}}+$ means stem pitting observed and - means no STEM pitting observed.

\section{Results}

Biological and molecular strain characterization. The four sources, B390-5, GFMS12-8, LMS6-6, and 'Maxi', were shown to be CTV single variants by using strain-specific RT-PCRs. Each source tested positive for one strain only in 'Duncan' grapefruit, sour orange, 'Mexican' lime, and 'Madam Vinous' sweet orange. Isolate B390-5 tested positive for the RB strain and was amplified with the group 2 differential RB primers (Cook et al. 2016). Isolate GFMS12-8 tested positive for strain T68, LMS6-6 for strain HA16-5, and 'Maxi' for strain VT. No other pathogens were detected in these sources, and direct sequencing of amplicons obtained using degenerate primers yielded single-variant sequences only. No stem pitting or stunting was induced by any of these isolates on either 'Madam vinous', the sweet orange host, or on sour orange. No 'seedling yellows' symptom was observed on the indicators, 'Duncan' grapefruit or sour orange, with these sources. All the isolates induced stem pitting on 'Mexican' lime and only LMS6-6 did not induce stem pitting on 'Duncan grapefruit'. These stem pitting results were similar to those found in the host range assessment (Table 1).

Complete genome sequences of three single-variant isolates, B390-5, 'Maxi', and LMS6-6 were generated and deposited in GenBank under the accession numbers KU883265, KU883266, and KU883267, respectively. A neighbor network reconstruction of the full-length genomes and other fully sequenced CTV strains (Fig. 1) displays the positioning of each single-variant in a different strain. The network shows clear separation of strains T36 and RB from the rest of the network, with the other groups being more loosely associated and interrelated to each other.

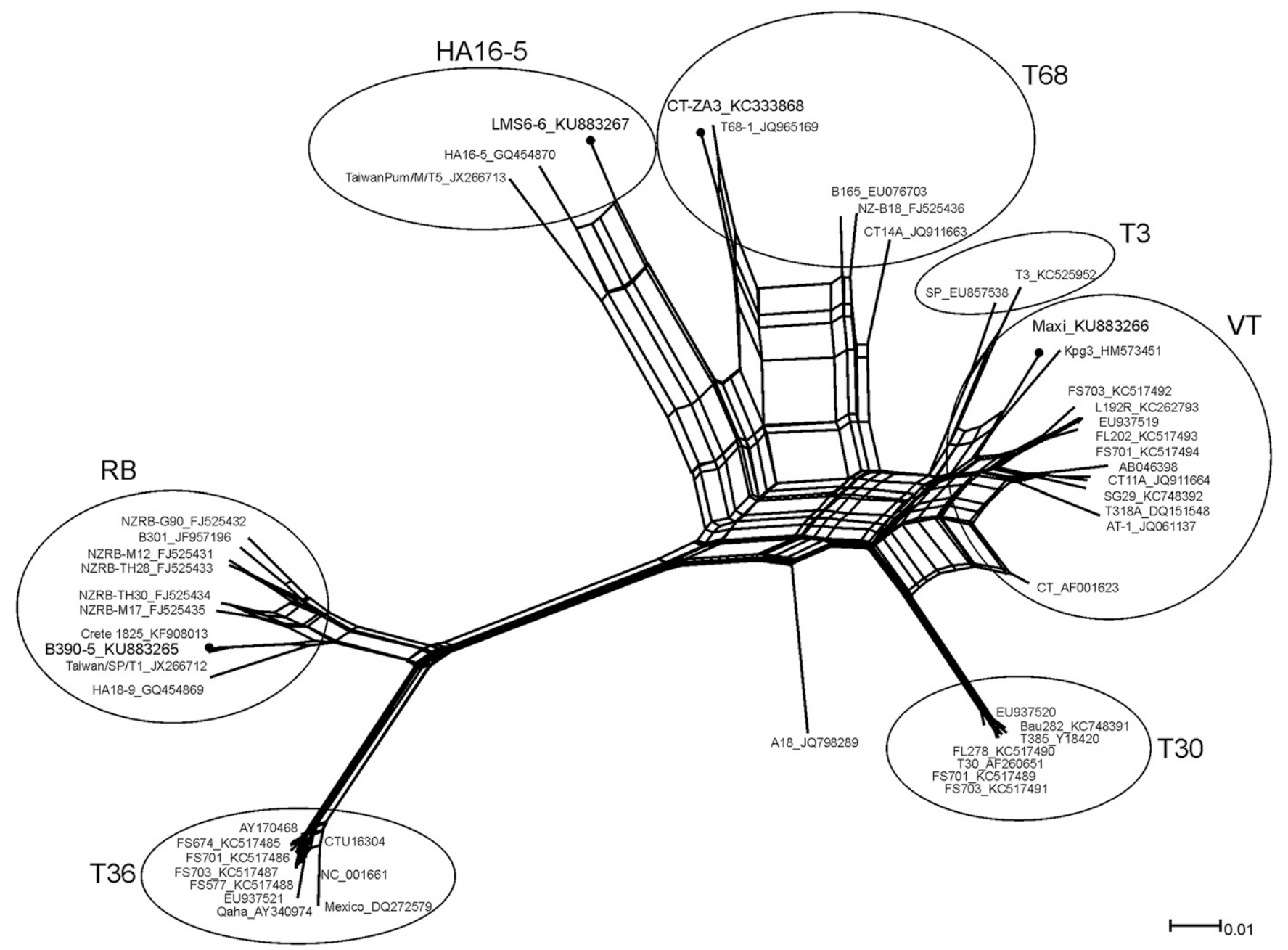

Fig. 1. Neighbor network reconstruction of the complete genomes of Citrus tristeza virus, including B390-5, GFMS12-8 (CT-ZA3), 'Maxi', and LMS6-6. 
Isolate B390-5 was shown to be a variant in the RB strain and shares a 99\% homology with Taiwan-Pum/SP/T1 (JX266712.1) and Crete 1825 (KF908013.1). The neighbor network construction of the full-length genomes illustrates these three isolates as a close grouping apart from the NZRB isolates and the Hawaiian isolate HA18-9 (GQ454869), which has a 3'-terminal half that has closer homology to HA16-5 than to the NZRB isolates (Melzer et al. 2010). Isolate 'Maxi' is a VT variant with closest homology (96\%) to Kpg3 (HM573451.1) and LMS6-6 was most similar to strain HA16-5 (GQ454870.1) (96\%). The genome of LMS6-6 clusters in a group with HA16-5 and TaiwanPum/M/T5 (JX266713) in the neighbor network construction, apart from the other strains. The GFMS128 genome was previously determined to be a T68 variant (Zablocki and Pietersen 2014).

Host-range symptom assessment. Stem pitting was observed in the four grapefruit varieties as well as in 'Mexican' lime inoculated with the single-variant CTV isolates as presented in Table 1. Only isolate LMS6-6 did not induce stem pitting in the grapefruit hosts. Stem pitting expression in grapefruit varieties was less pronounced than in 'Mexican' lime, the biological indicator host, and was unevenly distributed over the length of the shoots. The three isolates, B390-5, 'Maxi', and GFMS12-8, caused frequent stem pits at various assessment periods, but the frequency was not consistent and a rating scale could not produce a reliable indication of stem pitting severity due to this variation. No severe honey-comb stem pitting was obtained with any of these isolates in any of the host plants.
ELISA. Mean absorbance values of three semiquantitative CTV ELISA tests of four grapefruit varieties with the single-variant sources done at specific postinoculation intervals are presented in Figure 2. Results obtained for the four grapefruit varieties inoculated with isolate B390-5 showed that this CTV variant reached high titers in all four cultivars within the first two testing periods at 7 and 13 wpi as well as at 24 wpi, demonstrating efficient translocation and propagation within these grapefruit varieties. Subisolate GFMS12-8 was detected in all grapefruit varieties at each testing period, but titers were lower than B390-5 in all cases. Viral titer of the 'Maxi' isolate, obtained at both 7 and 13 weeks, were comparatively low in all grapefruit varieties, but titers were higher at 24 weeks, when the isolate was detected at high titers in both 'Duncan' and 'Star Ruby' but not in 'Marsh' and 'Nel Ruby'. Isolate LMS6-6 reached high titers at the 24-week sampling point, but detection varied at 7 and 13 weeks when detection levels were higher in the two white grapefruit varieties 'Duncan' and 'Marsh', compared with the red varieties 'Nel Ruby 'and 'Star Ruby'. Viral detection levels in 'Mexican' lime did not follow the same patterns as in the grapefruit varieties (Fig. 2), with noticeable differences obtained with isolates LMS6-6 and 'Maxi'.

Field trial assessment of B390-5 on grapefruit. As presented in Tables 2 and 3, 'Star Ruby' and 'Marsh' trees infected with isolate B390-5 performed well compared with the other treatments. Stem pitting observed with isolate B390-5 on 'Star Ruby' was within an acceptable range in which tree performance was not impeded. The 'Star Ruby' trees were significantly larger than those containing
A
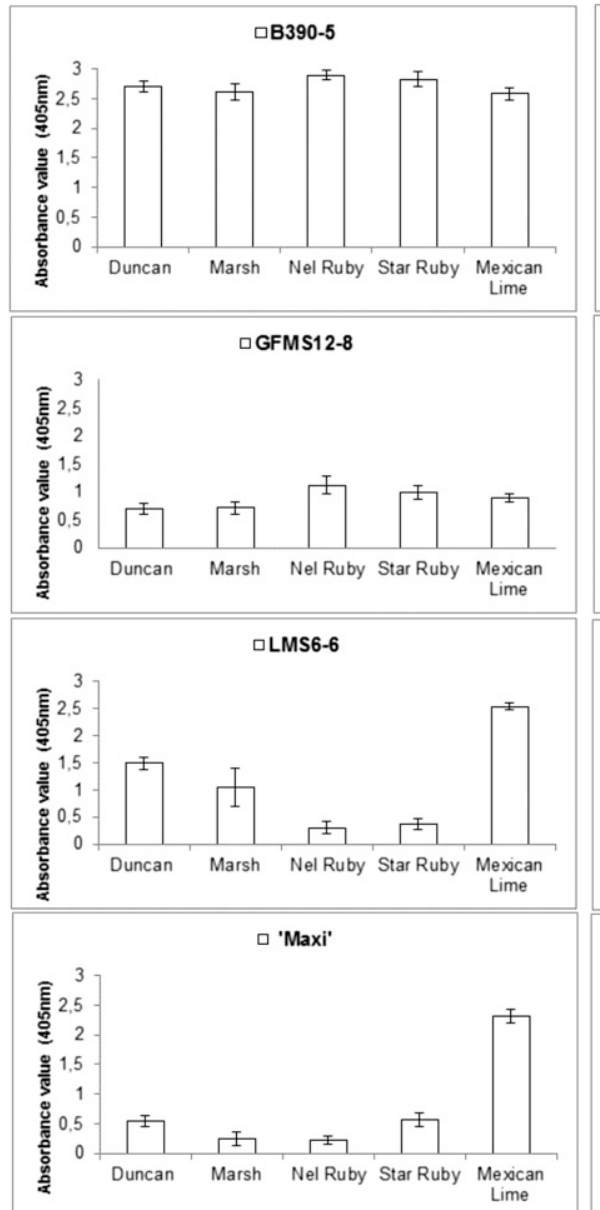

B
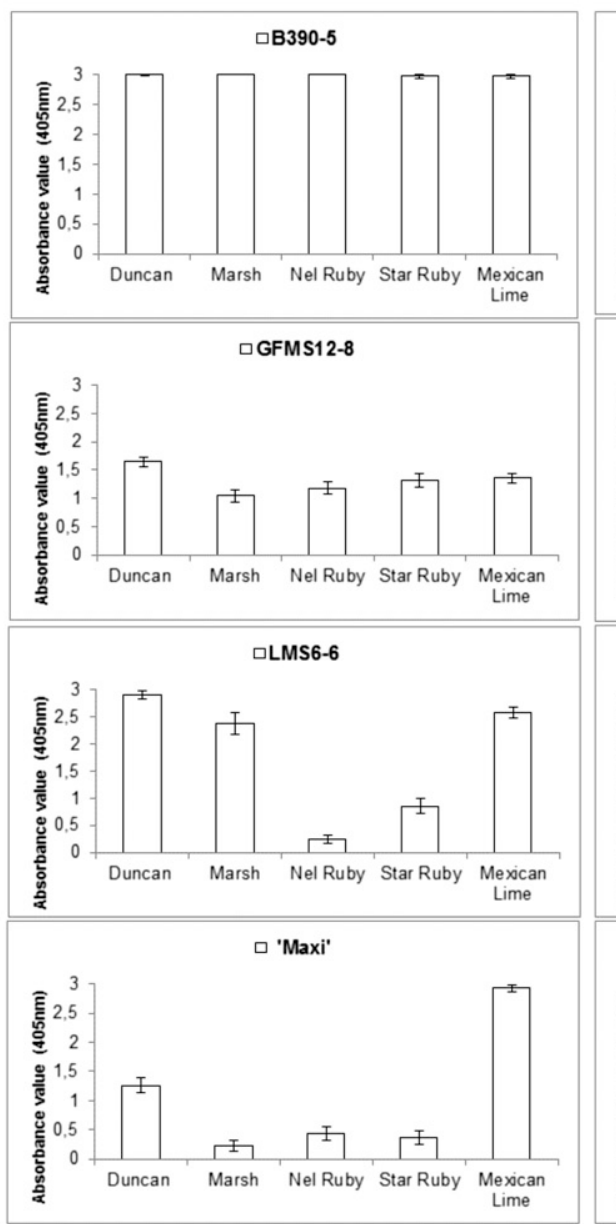

C

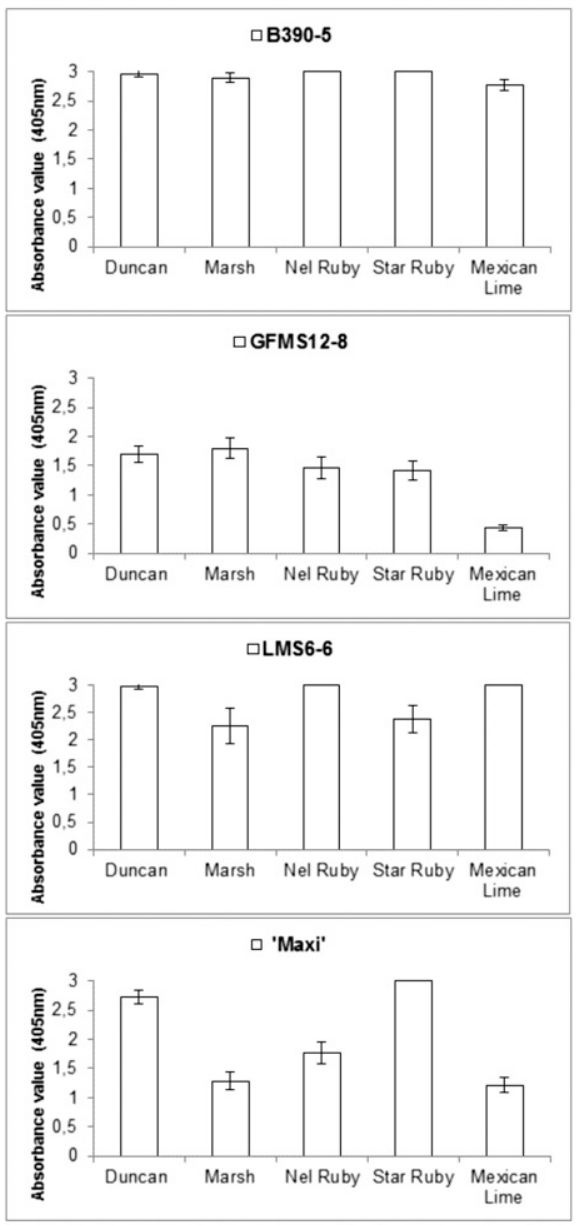

Fig. 2. Mean $(n=5)$ absorbance values at $405 \mathrm{~nm}$ obtained after $30 \mathrm{~min}$ for Citrus tristeza virus (CTV) enzyme-linked immunosorbent assay tests of grapefruit varieties 'Duncan', 'Marsh', 'Nel Ruby', and 'Star Ruby' inoculated with single-variant isolates B390-5, GFMS12-8, LMS6-6, and 'Maxi', compared with the 'Mexican' lime (CTV indicator host). Leaves were sampled A, 7 weeks postinoculation (wpi), $15 \mathrm{~cm}$ above inoculation point, B, 13 wpi, $30 \mathrm{~cm}$ above inoculation point, and C, 24 wpi at the top of the plant. Standard error bars are shown. 
GFMS35 or GFMS12 and the 3-year average cumulative yield was significantly higher than the other treatments. Similarly, mild stem pitting was observed on the 'Marsh' trees, which did not impede tree growth or influence yield. In contrast, however, 'Star Ruby' and 'Marsh' trees inoculated with the GFMS12 source developed severe stem pitting. The stem pitting in 'Star Ruby' inhibited tree growth and decreased fruit size significantly. GFMS12 also induced severe stem pitting on 'Marsh', and this did correlate to a decrease in canopy volume but not as significantly as seen on the more sensitive 'Star Ruby'.

\section{Discussion}

The ability of CTV strains or variants to induce severe stem pitting that can diminish yield and fruit size, and conversely, the ability to reduce disease expression with cross-protection strategies is important for the grapefruit industry. Parameters that define a good cross-protecting source, apart from disease mitigation, include the ability of the virus to rapidly translocate to all parts of the plant and induce no or mild symptoms in the target cultivar but, also, in other citrus types (Lee et al. 1987). The ability of the virus to rapidly translocate in the host is important to ensure that the virus is proliferated in the bud-wood material supplied to industry. Isolate B390-5 was the only single-strain variant of the four tested that translocated rapidly and that was consistently detected at high titers in four grapefruit varieties, which makes this isolate a good candidate to evaluate further as a cross-protection source for grapefruit. Low titer and variable translocation of isolates GFMS12-8, LMS6-6, and 'Maxi' in the grapefruit hosts diminish their potential value as candidates for cross-protection sources in grapefruit.

Single-variant isolate GFMS12-8, sequenced as CT-ZA3, a T68 variant (Zablocki and Pietersen 2014), induced stem pitting in both grapefruit and 'Mexican' lime. This isolate was subisolated from the GFMS12 source, which was previously used as a cross-protection source for grapefruit in South Africa until probable segregation of strains gave rise to severe stem pitting (van Vuuren and Manicom 2005). It is still unclear which strains or variants were responsible for the severe stem pitting and how the original GFMS12 virus population structure changed over time. It was, therefore, relevant to determine the pathogenicity of components of this source, which includes GFMS12-8. Although frequent stem pitting was obtained with this isolate in the glasshouse, the frequency was not consistent in the various evaluations. No severe honey-comb stem pitting was observed that would associate this variant with the severe symptoms that were later obtained with GFMS12.

The complete genome of the 'Maxi' isolate confirmed it to be a variant of the VT strain, with closest homology (96\%) to the Indian isolate $\mathrm{Kpg} 3$, a mandarin (C. reticulata) decline isolate, which was characterized on a host range excluding grapefruit. Stunting and chlorosis was observed in sweet orange, but no stem pitting was seen

Table 2. Stem pitting severity, tree size, 3-year cumulative yield, and \% small fruit of 'Star Ruby' grapefruit trial trees inoculated with various Citrus tristeza virus $(\mathrm{CTV})$ sources, 8 years after planting

\begin{tabular}{|c|c|c|c|c|}
\hline \multirow[b]{2}{*}{ Treatment $^{\mathrm{x}}$} & \multicolumn{4}{|c|}{ Stem pitting rating and production measurements ${ }^{\mathrm{w}}$} \\
\hline & $\begin{array}{l}\text { Stem } \\
\text { pittingy }\end{array}$ & $\begin{array}{c}\text { Canopy } \\
\text { volume }\left(\mathbf{m}^{\mathbf{3}}\right)\end{array}$ & $\begin{array}{c}\text { Cumulative } \\
\text { yield (kg/tree) }\end{array}$ & $\begin{array}{c}\text { \% small fruit } \\
\text { (8th year) }\end{array}$ \\
\hline B390-5 & $0.8 \mathrm{~B}$ & $22 \mathrm{~A}$ & $524 \mathrm{~A}$ & $7 \mathrm{C}$ \\
\hline Control & $0.0 \mathrm{~B}$ & $21 \mathrm{AB}$ & $445 \mathrm{~B}$ & $3 \mathrm{C}$ \\
\hline GFMS35 & $0.5 \mathrm{~B}$ & $15 \mathrm{BC}$ & $343 \mathrm{C}$ & $28 \mathrm{~B}$ \\
\hline GFMS12 & $3.0 \mathrm{~A}$ & $11 \mathrm{C}$ & $347 \mathrm{C}$ & $64 \mathrm{~A}$ \\
\hline Prob F treat ${ }^{2}$ & 0.0001 & 0.012 & 0.0003 & 0.0001 \\
\hline
\end{tabular}

${ }^{w}$ Data presented are the means of five trees per treatment. Treatments with the same letters for Fisher least square difference do not statistically differ.

$x$ CTV sources applied and uninoculated control.

${ }^{y}$ rating scale: $0=$ smooth trunk with no visible pits, $1=$ one to three grooves on the stem, $2=$ multiple grooves that do not coalesce, and $3=$ severe stem pitting in which numerous grooves coalesce to form a knotted appearance.

$\mathrm{z}$ Probability value from analysis of variance for differences between treatments. in any of the hosts, including two lime varieties (Biswas 2010). The 'Maxi' isolate did, however, cause stem pitting in 'Mexican' lime, indicating probable phenotypic differences between these isolates. As with GFMS12-8, no severe honey-comb stem pitting was obtained with the 'Maxi' isolate, which would have classed this variant as a severe pathogen of grapefruit. LMS6-6 induced no stem pitting in any of the grapefruit varieties and does not appear to be detrimental to grapefruit, based on the glasshouse trial. The genome sequence of LMS6-6 also validates the status of the HA16-5 clade as a separate CTV strain, as three full-length genomes are now characterized and cluster apart from the other strains.

Isolate B390-5 showed closest sequence homology (99\%) to two isolates, Taiwan-Pum/SP/T1 and Crete 1825. Taiwan-Pum/SP was subisolated from a field isolate, CTV-D, by aphid transmission (Tsai et al. 1993). The stem pitting induced by CTV-D was described as numerous deep linear pits showing gumming on grapefruit and pummelo, which was associated with shortened internodes and stunting. Coalescing pits formed grooves in the stem surface that displayed a fluted appearance (Su 1981), but it is uncertain whether this original field isolate was a single-strain source. The subisolate, Taiwan-Pum/SP, caused stem pitting on pummelo but no stem pitting on 'Mexican' lime after two-month intervals in glasshouse trials; however, assessments that this variant was solely responsible for severe grapefruit dwarfing and stem pitting in the field is unconfirmed (Tsai et al. 1993). No associated symptoms were reported or biological data presented with the report of the Crete 1825 genome sequencing (Owen et al. 2014), although severity was assumed based on the first report of the CTV-D field isolate ( $\mathrm{Su} \mathrm{1981).} \mathrm{Contrary} \mathrm{to} \mathrm{findings} \mathrm{obtained} \mathrm{with} \mathrm{Taiwan-}$ Pum/SP, isolate B390-5 induced stem pitting on 'Mexican' lime in the current study. Assessment periods in this study were longer than those reported for the Taiwan-Pum/SP isolate and evaluations were done at intervals of six months to a year, which could account for the difference in reaction in 'Mexican' lime. Stem pitting was obtained in all grapefruit cultivars and, similar to isolates 'Maxi' and GFMS128 , no severe honey-comb stem pitting was observed.

Evaluation of field trees inoculated with isolate B390-5 in two grapefruit trials, showed that, although the isolate was associated with stem pitting, it did not impede tree growth, yield, or fruit size during the 8-year evaluation period. Horticulturally, both 'Star Ruby' and 'Marsh' trees containing this isolate performed better than those with GFMS35, the current cross-protection source, when comparing canopy volume, production, and fruit size. 'Star Ruby' trees containing GFMS35 showed less stem pitting than trees inoculated with isolate B390-5, but canopy volumes and yields were smaller than trees containing the RB isolate. This suggests that the influence of CTV on tree performance might not be limited to the effect of stem pitting only. The cross-protecting ability of isolate B390-5 could, however, not be assessed in these trials, as no severe challenge was observed in either trial, based on the absence of any externally visible stem

Table 3. Stem pitting severity, tree size, 3-year cumulative yield, and $\%$ small fruit of 'Marsh' grapefruit trial trees inoculated with various Citrus tristeza virus (CTV) sources, 8 years after planting

\begin{tabular}{lcccc}
\hline & \multicolumn{4}{c}{ Stem pitting rating and production measurements } \\
\cline { 2 - 5 } & $\begin{array}{c}\text { Stem } \\
\text { pitting }\end{array}$ & $\begin{array}{c}\text { Canopy } \\
\text { volume }\left(\mathbf{m}^{\mathbf{3}}\right)\end{array}$ & $\begin{array}{c}\text { Cumulative } \\
\text { yield (kg/tree) }\end{array}$ & $\begin{array}{c}\text { \% small fruit } \\
\text { (8th year) }\end{array}$ \\
\hline B390-5 & $0.6 \mathrm{~B}$ & $31 \mathrm{~A}$ & $347 \mathrm{~A}$ & $5 \mathrm{~A}$ \\
Control & $0.0 \mathrm{C}$ & $30 \mathrm{~A}$ & $290 \mathrm{~A}$ & $5 \mathrm{~A}$ \\
GFMS35 & $0.0 \mathrm{C}$ & $23 \mathrm{AB}$ & $267 \mathrm{~A}$ & $8 \mathrm{~A}$ \\
GFMS12 & $2.8 \mathrm{~A}$ & $21 \mathrm{~B}$ & $256 \mathrm{~A}$ & $14 \mathrm{~A}$ \\
Prob F treat $^{\mathrm{z}}$ & 0.0001 & 0.042 & - & - \\
\hline
\end{tabular}

${ }^{w}$ Data presented are the means of five trees per treatment. Treatments with the same letters for Fisher least square difference do not statistically differ.

$x$ CTV sources applied and uninoculated control.

y rating scale: $0=$ smooth trunk with no visible pits, $1=$ one to three grooves on the stem, $2=$ multiple grooves that do not coalesce and $3=$ severe stem pitting in which numerous grooves coalesce to form a knotted appearance.

z Probability value from analysis of variance for differences between treatments 
pitting on the control trees. The ability to moderate the effects of severe strains in cross-protection can only be confirmed by challenge experiments and in field trials in which the challenge pressure of severe strains is high.

Severe stem pitting and stunting was noticeable on field trees inoculated with GFMS12, a severe source, 3 years after planting (data not presented). Given that stem pitting assessment periods in the glasshouse trial were just less than a year, the stem pitting results can only be used as indicative of possible detrimental influence, unless very severe stem pitting was consistently found that induced stunting or other observable negative effects, which was not the case in this study. Conversely, though, and as demonstrated with isolate B390-5, stem pitting observed in the glasshouse and field trials did not always result in a negative influence on the overall performance of the trees.

The effects that CTV strains and variants may have on tree health and production of commercial varieties cannot be extrapolated from results obtained from short-term glasshouse trials. Although these may be indicative, the impact of CTV strains and variants can ultimately only be determined in long-term field trials under various climatic conditions.

Single-variant CTV sources of VT, RB, T68, and HA16-5 strains were identified and characterized in grapefruit hosts. These isolates did not induce severe stem pitting in commercial grapefruit varieties in a glasshouse trial. Of further significance is that results obtained with the RB isolate B390-5 did not support the detrimental findings in grapefruit, previously reported for the homologous isolate Taiwan-Pum/SP/T1 (Tsai et al. 1993). Two field trials testing two grapefruit varieties demonstrated no deleterious horticultural effects associated with this isolate in either 'Star Ruby' or 'Marsh' grapefruit. The single-variant sources characterized are valuable for further complementation studies to identify components required for cross-protection in grapefruit.

\section{Acknowledgments}

The authors would like to acknowledge Citrus Research International (projects 742 and 1100) and the Technology and Human Resources for Industry Programme (Department of Trade and Industry, South Africa, grant TP13081327563) for their financial assistance towards this research. Opinions expressed and conclusions arrived at are those of the authors and are not necessarily to be attributed to the National Research Foundation.

\section{Literature Cited}

Altschul, S. F., Gish, W., Miller, W., Myers, E. W., and Lipman, D. J. 1990. Basic local alignment search tool. J. Mol. Biol. 215:403-410.

Atallah, O. O., Kang, S. H., El-Mohtar, C. A., Shilts, T., Bergua, M., and Folimonova, S. Y. 2016. A 5'-proximal region of the Citrus tristeza virus genome encoding two leader proteases is involved in virus superinfection exclusion. Virology 489:108-115.

Bederski, K., Roistacher, C. N., and Müller, G. W. 2005. Cross protection against the severe Citrus tristeza virus stem pitting in Peru. Pages 117-125 in: Proceedings of the 16th Conference of the International Organization of Citrus Virologists (IOCV), Monterrey, Mexico. M. E. Hilf, N. Duran Vila, and M. A. Rocha-Peña, eds. IOCV, University of California, Riverside, CA.

Biswas, K. K. 2010. Molecular characterization of Citrus tristeza virus isolates from the northeastern Himalayan region of India. Arch. Virol. 155:959-963.

Broadbent, P., Bevington, K. B., and Coote, B. G. 1991. Control of stem pitting of grapefruit in Australia by mild strain protection. Pages 64-70 in: Proceedings of the 11th Conference of the International Organization of Citrus Virologists (IOCV), Orlando, FL. R. H. Brlansky, R. F. Lee, and L. W. Timmer, eds. IOCV, University of California, Riverside, CA.

Burger, W. T., Vincent, A. P., Barnard, C. J., du Plessis, J. A., and Smith, J. H. E. 1970. Metodes waarvolgensdie grootte van sitrusbome bepaal kan word. S. Afr. Citrus J. 433:13-15.

Cook, G., van Vuuren, S. P., Breytenbach, J. H. J., Burger, J. T., and Maree, H. J. 2016. Expanded Strain-specific RT-PCR assay for differential detection of currently known Citrus tristeza virus strains: A useful screening tool. J. Phytopathol. Published online. doi:10.1111/jph.12454

Dress, A. W., and Huson, D. H. 2004. Constructing splits graphs. IEEE/ACM TCBB 1:109-115.
Folimonova, S. Y. 2012. Superinfection exclusion is an active virus-controlled function that requires a specific viral protein. J. Virol. 86:5554-5561.

Folimonova, S. Y., Robertson, C. J., Shilts, T., Folimonov, A. S., Hilf, M. E., Garnsey, S. M., and Dawson, W. O. 2010. Infection with Strains of Citrus Tristeza Virus Does Not Exclude Superinfection by Other Strains of the Virus. J. Virol. 84:1314-1325.

Gambette, P., and Huson, D. H. 2008. Improved layout of phylogenetic networks. IEEE/ACM TCBB 5:472-479.

Hall, T. A. 1999. BioEdit: A user-friendly biological sequence alignment editor and analysis program for Windows 95/98/NT. Nucleic Acids Symp. Ser. 41: 95-98.

Harper, S. J. 2013. Citrus tristeza virus: Evolution of Complex and Varied Genotypic Groups. Front. Microbiol. 4:93.

Huson, D. H., and Bryant, D. 2006. Application of phylogenetic networks in evolutionary studies. Mol. Biol. Evol. 23:254-267.

Karasev, A. V., Boyko, V. P., Gowda, S., Nikolaeva, O. V., Hilf, M. E., Koonin, E. V., Niblett, C. L., Cline, K., Gumpf, D. J., Lee, R. F., Garnsey, S. M., Lewandowski, D. J., and Dawson, W. O. 1995. Complete sequence of the Citrus tristeza virus RNA genome. Virology 208:511-520.

Lee, R. F., Brlansky, R. H., Garnsey, S. M., and Yokomi, R. K. 1987. Traits of Citrus tristeza virus important for mild strain cross protection of citrus: The Florida approach. Phytophylactica 19:215-218.

Marais, L. J. 1994. Citrus tristeza virus and its effect on the southern Africa citrus industry. Citrus Ind. 75:58-60.

Melzer, M. J., Borth, W. B., Sether, D. M., Ferreira, S., Gonsalves, D., and Hu, J. S. 2010. Genetic diversity and evidence for recent modular recombination in Hawaiian Citrus tristeza virus. Virus Genes 40:111-118.

Moreno, P., and Garnsey, S. M. 2010. Citrus tristeza diseases-A worldwide perspective. Pages 27-49 in: Citrus tristeza virus Complex and Tristeza Diseases. Karasev, A., and Hilf, M. E., eds. The American Phytopathological Society, St. Paul, MN.

Owen, C., Mathioudakis, M., Gazivoda, A., Gal, P., Nol, N., Kalliampakou, K. Figas, A., Bellan, A., Iparaguirre, A., Rubio, L., and Livieratos, I. 2014 Evolution and molecular epidemiology of Citrus tristeza virus on Crete: Recent introduction of a severe strain. J. Phytopathol. 162:839-843.

Roy, A., and Brlansky, R. H. 2010. Genome analysis of an orange stem pitting citrus tristeza virus isolate reveals a novel recombinant genotype. Virus Res. 151:118-130.

Salibe, A. A., Souza, A. A., Targon, M. L. P. N., and Müller, G. W. 2002. Selection of a mild sub-isolate of Citrus tristeza virus for preimmunization of Pera sweet orange. Pages 348-351 in: Proceedings of the 15th conference of the International Organization of Citrus Virologists (IOCV), Paphos, Cyprus. N. duran Vila, R. G. Milne and J. V. da Graca, eds. IOCV, University of California, Riverside, CA

Su, H.-J. 1981. A tristeza virus strain causing dwarf of pomelo and grapefruit Pages 423-426 in: Proceedings of the International Society of Citriculture, Tokyo. K. Matsumoto, C. Oogaki, I. Kozaki, K. Kadoya, F. Mizutani, and E. Yuda, eds. International Society of Citriculture, University of California, Riverside, CA.

Tatineni, S., and Dawson, W. O. 2012. Enhancement or Attenuation of Disease by Deletion of Genes from Citrus Tristeza Virus. J. Virol. 86:7850-7857.

Tatineni, S., Robertson, C. J., Garnsey, S. M., and Dawson, W. O. 2011. A plant virus evolved by acquiring multiple nonconserved genes to extend its host range. Proc. Natl. Acad. Sci. U.S.A. 108:17366-17371.

Tsai, M.-C., Su, H.-J., and Garnsey, S. M. 1993. Comparative Study on StemPitting Strains of CTV in the Asian Countries. Pages 16-19 in: Proceedings of the 12th Conference of the International Organization of Citrus Virologists (IOCV), New Delhi, India. P. Moreno, J. V. da Graca, and L. W. Timmer, eds. IOCV, University of California, Riverside, CA.

van Vuuren, S. P., and Manicom, B. Q. 2005. The response of Star Ruby grapefruit to different Citrus tristeza virus isloates. Pages 112-116 in: Proceedings of the 16th Conference of the International Organization of Citrus Virologists (IOCV), Monterrey, Mexico. M. E. Hilf, N. Duran Vila, and M. A. Rocha-Peña, eds. IOCV, University of California, Riverside, CA.

van Vuuren, S. P., van der Vyver, J. B., and Luttig, M. 2000. Diversity among sub-isolates of cross-protecting Citrus tristeza virus isolates in South Africa. Pages 103-110 in: Proceedings of the 14th Conference of the International Organization of Citrus Virologists (IOCV), Campinas, Brazil. J. V. da Graca, R. F. Lee, and R. K. Yokomi, eds. IOCV, University of California, Riverside, CA.

Zablocki, O., and Pietersen, G. 2014. Characterization of a novel Citrus tristeza virus genotype within three cross-protecting source GFMS12 sub-isolates in South Africa by means of Illumina sequencing. Arch. Virol. 159:2133-2139. 